\title{
Native T1 mapping correlates with severity of microvascular dysfunction measured by coronary flow reserve (CFR) in acute myocardial infarction
}

\author{
Erica Dall'Armellina2 ${ }^{*}$, Florim Cuculi², Joyee Basu², Robin House², Stefan K Piechnik', Keith Channon², Colin Forfar², \\ Bernard D Prendergast ${ }^{2}$, Rajesh Kharbanda², Stefan Neubauer ${ }^{1}$, Robin Choudhury ${ }^{2}$
}

From 17th Annual SCMR Scientific Sessions

New Orleans, LA, USA. 16-19 January 2014

\section{Background}

Native T1 mapping cardiac magnetic resonance (CMR) imaging allows for quantitative assessment of myocardial oedema following acute myocardial infarction (MI). Coronary flow reserve (CFR) measures the maximum increase in intracoronary blood flow and it is a marker of microvascular dysfunction consequent to ischemic damage. The relation between increasingly higher native T1 values and the underlying severity of microvascular damage due to ischemic insult is not known.We hypothesise that $\mathrm{T} 1$ values measured in areas of injured myocardium, correlate to invasive measurements of CFR and microvascular dysfunction.

\section{Methods}

We recruited $20 \mathrm{ST}$ elevation MI (STEMI) patients post primary percutaneous coronary intervention. At 24 hours post procedure the patients underwent a repeat coronary angiogram with CFR measurement, and a 3T CMR. Matching short axis slices with full left ventricle (LV) coverage were acquired using functional steady-state free precession (SSFP) imaging, native T1 mapping, oedema T2W imaging and late gadolinium enhancement (LGE). For the comparisons among acute T1-mapping, T2W and LGE, we excluded apical slices due to partial volume effects and slices with off-resonance artifacts. In order to minimise ambiguity over acutely injured myocardium with low signal intensity and low T1 due to microvascular obstruction (MVO), patients with MVO on LGE were excluded from analyses. Each slice was segmented in a 6 equiangular segment model with the RV-LV junction as reference point.
Global and segmental injured fractions by LGE and oedema were assessed; segmental T1 values were calculated in the injured myocardial segments with an injured fraction of at least $50 \%$ as determined by oedema and/or LGE.

\section{Results}

Out of the recruited patients, 6 were excluded due to microvascular obstruction on LGE. Fourteen underwent CMR and CFR at 24 hrs. The EF was $53 \pm 10 \%$, with a LV damaged fraction measured by oedema and LGE of $37 \pm$ $15 \%$ and $30 \pm 13 \%$. The average $\mathrm{T} 1$ values in the injured areas were $1295 \pm 61 \mathrm{msec}$ (mean $\pm \mathrm{SD}$, range 1159-1388 $\mathrm{msec}$ ) (normal values $=1196 \pm 56 \mathrm{msec})$. There was a significant correlation $(\mathrm{r}=-0.7, \mathrm{p}<0.01)$ between the $24 \mathrm{hrs}$

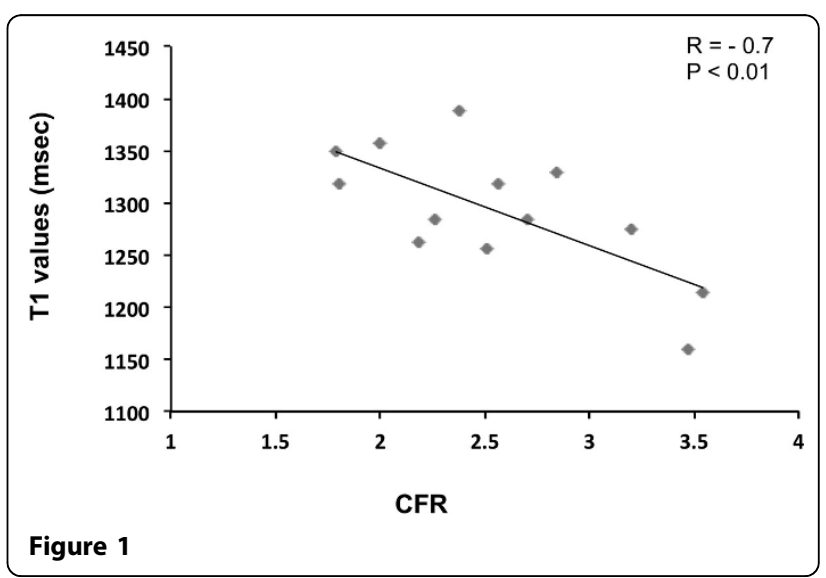


CFR and the average $\mathrm{T} 1$ value in the affected myocardium (Figure 1).

\section{Conclusions}

Increasingly higher native $\mathrm{T} 1$ values correlate with the severity of myocardial injury assessed by invasive CFR at 24 hours post STEMI.

\section{Funding}

Oxford Biomedical Research Centre.

\section{Authors' details}

${ }^{1}$ Radcliffe Department of Medicine Division ofCardiovascular Medicine, University of Oxford Centre for Clinical Magnetic Resonance Research, Oxford, UK. ${ }^{2}$ Radcliffe Department of Medicine Division of Cardiovascular Medicine, The Oxford Acute Vascular Imaging Centre (AVIC), Oxford, UK.

Published: 16 January 2014

doi:10.1186/1532-429X-16-S1-P191

Cite this article as: Dall'Armellina et al.: Native T1 mapping correlates

with severity of microvascular dysfunction measured by coronary flow

reserve (CFR) in acute myocardial infarction. Journal of Cardiovascular

Magnetic Resonance 2014 16(Suppl 1):P191.

Submit your next manuscript to BioMed Central and take full advantage of:

- Convenient online submission

- Thorough peer review

- No space constraints or color figure charges

- Immediate publication on acceptance

- Inclusion in PubMed, CAS, Scopus and Google Scholar

- Research which is freely available for redistribution

Submit your manuscript at www.biomedcentral.com/submit 